\title{
¿CÓMO MEDIR EL FENÓMENO URBAN SPRAWL A TRAVÉS DE INDICADORES PAISAJÍSTICOS? APLICACIÓN A LA ISLA DE TENERIFE
}

\author{
Miguel Ángel Mejías Vera \\ Departamento de Geografía. Universidad de La Laguna \\ mmejias@ull.es
}

\section{RESUMEN}

La dispersión urbanística extensiva es uno de los grandes problemas de paisaje que existen en la actualidad. Si el proceso de dispersión se produce en un espacio insular, que es limitado y finito, las consecuencias son más graves. Su análisis y medición utilizando indicadores de la ecología del paisaje es uno de los principales objetivos de este artículo. Para definir la unidad de referencia de análisis utilizo dos escalas: la primera es la dimensión insular (Tenerife), entendida como marco de referencia máximo, la segunda, desciende a lo que entiendo como unidad mínima de referencia, en este caso, el paraje catastral definido en el catastro de naturaleza rústica de 1956. La estructura viaria y el espacio edificado son las componentes que sustentan esta investigación.

Palabras clave: Urban sprawl, ecología del paisaje, paisaje, suelo rústico industrial, paraje catastral.

\section{ABSTRACT}

Extensive urban sprawling is currently one of the main problems in landscapes. When the sprawling process occurs within the limited and finite area of an island, the consequences are even more severe. The objective of this article is the analysis and measurement of this sprawling using landscape ecology indicator. In order to define the analysis reference unit, two different scales will be used: the first scale is the insular dimension (Tenerife), which must be understood as a maximum reference framework; the second scale must be

Fecha de recepción: diciembre 2010.

Fecha de aceptación: enero 2013. 
interpreted as a minimum unit of reference, in this case, the cadastral area defined by the cadastral register of rustic land in 1956. The road structure and the constructed area are the main components of this research.

Key words: Urban sprawl, landscape ecology, landscape, industrial rustic land, cadastral, cadastral area.

\section{DEFINICIÓN DEL PROBLEMA. HIPÓTESIS}

Históricamente, desde tiempos prehispánicos, las rutas de comunicación de la isla de Tenerife, dada sus dificultades orográficas, se diseñaron circunvalando el perímetro insular en tres niveles altitudinales: por un lado, el camino que comunica los diferentes menceyatos ${ }^{1}$ situado en las cotas próximas a la línea de costa y medianía baja; por otro, el camino que bordea la zona alta de pastoreo; por último, en la cumbre, la ruta de la cordillera y de Las Cañadas del Teide (Cuscoy, 1968: 119). Estas tres grandes rutas se estructuran transversalmente mediante la intensa red de rutas de trashumancia. Una vez producida la conquista y colonización de esta isla de realengo en 1496, la red se intensifica de manera radial a partir de la fundación, en ese momento, de la ciudad de San Cristóbal de La Laguna. Los caminos ya trazados se van mejorando y adaptando a las necesidades socioeconómicas de cada momento. El desarrollo se centra fundamentalmente en los dos ejes transversales: el de barlovento, entre La Laguna y Garachico (E-W); y el de sotavento, entre La Laguna y Adeje (NE-SW-NW). Es ya en el siglo XIX donde se empiezan a conformar las dos carreteras generales que enlazan los diferentes núcleos de población situados en las medianías insulares, donde la riqueza de suelo y la existencia de agua fundamentan su posición. La localización extrema de la ciudad de La Laguna en el conjunto insular potencia la estructura viaria focal respecto a la radial.

En la actualidad, el sistema de comunicación multimodal terrestre (transporte por carretera y tren ligero), y aéreo (aeropuertos de Tenerife Norte y Tenerife Sur), junto al desarrollo de los futuros proyectos de transporte férreo, hacia al Norte y Sur, consolida esta hipótesis. Los asentamientos tradicionales concentrados y los núcleos urbanos y turísticos vinculados a esta estructura viaria explosionan en un largo diseminado de viviendas de escasa densidad y poco rigor tipológico a partir de los años 60 del siglo XX. Estamos, por tanto, en la configuración del modelo de desarrollo territorial actual, en el que la edificación diseminada del espacio paraurbano (Folch, 2003)² y la edificación en suelo rústico conforman, no sólo el mayor número de piezas edificadas, sino que ocupa más superficie que los núcleos urbanos. Este hecho se agudiza aún más si excluimos de la superficie total insular el espacio ocupado por el espacio biótico y el abiótico, en su mayoría declarado espacio protegido. Parto de la hipótesis de que la red es claramente el eje que facilita y canaliza el fenómeno del urban sprawl.

1 «Los menceyatos son divisiones en comarcas naturales» que los aborígenes de la isla de Tenerife poseían, pero «además se justificaba por una potente razón económica». Podríamos entender esta relación como la configuración de las primeras unidades de paisaje.

2 Las tipologías paraurbanas incluyen el espacio periurbano, el rurubano y el vorurbano. 
Una de las dificultades en la ordenación del paisaje de Tenerife es el descontrol de la edificación paraurbana y el tratamiento del espacio no consolidado contiguo. Este proceso agrava la complejidad de ordenación y planificación del espacio ocupado por las demás componentes paisajísticas culturales. El espacio cultural (33\%) -abiótico (8\%) y biótico (59\%)-, es el de mayor fragilidad paisajística, y por tanto, el que requiere una mayor preocupación.

\section{JUSTIFICACIÓN DEL PROBLEMA}

Mi intención es aplicar algunos indicadores que me permitan, de manera exploratoria, definir y evaluar los modelos de dispersión edificatoria en el suelo paraurbano, de la isla de Tenerife.

El análisis de los suburbios va ligado a la aparición de los espacios urbanos, pero es a partir de los años cincuenta y sesenta del siglo XX cuando comienzan a aparecer nuevos conceptos como el de Dispersion sheet, (Lynch, 1961) o el espectro (Wallace-Mcharg, 1963, 2000). Son formas de denominar al proceso típico de crecimiento suburbano de una región metropolitana. Este fenómeno de urbanismo rudimentario (McHarg, 1963, 2000) es ya, en esa época, una de las grandes preocupaciones contemporáneas y, por tanto, un desafío para la ordenación del territorio en todo el planeta. Este desarrollo tiene múltiples etapas y formas de crecimiento: ensanches, polígonos, ciudad jardín, y especialmente, asentamientos de urbanización marginal. Son estos espacios los que resultan del trasvase de la población hacia la periferia. El procedimiento se realiza mediante procesos de ordenación y parcelación previos a la edificación, pero que no tienen ninguna previsión ni tampoco la construcción de servicios de urbanización. Por tanto, no son integrados en el ámbito de planeamiento sino que son considerados clandestinos. Éste es el proceso de formación de la ciudad marginal de Santa Cruz de Tenerife (García, 1981).

Hoy, el fenómeno que técnicamente se viene a denominar urban sprawl o suburban sprawl (O’Meara, 2004, Muñiz y García-López, 2007, Jaeger, 2010), se caracteriza por contener espacios constituidos por edificaciones de baja densidad (Tarroja, 2009: 240), desestructuradas y amorfas, que generan problemas vinculados al aumento de las distancias temporales y espaciales entre la residencia familiar y los diferentes centros de destino (trabajo, enseñanza, ocio, etc.), y que conlleva, entre otros aspectos, la dependencia del vehículo privado, la generación de espacios de exclusión (García, Smith y Mejías, 2007) ${ }^{3}$, y el alto costo que supone la gestión y el mantenimiento de las infraestructuras y servicios. También, se utiliza el término de sprawlscape o paisaje de la dispersión (Ingersoll, 1999), en el que el proceso de urbanización ha producido un paisaje, dónde «las manchas de aceite», se multiplican alrededor de autopistas y rotondas (Muñoz, 2009). Según la Agencia Europea de Medioambiente (EEA), «Urban sprawl is commonly used to describe physically expanding urban areas», $\mathrm{y}$ «has described sprawl as the physical pattern of low-density expansion of large urban areas, under market conditions, mainly into the surrounding agricultural areas». Para el profesor Jochen A. G. Jaeger junto a otros investigadores suizos -Bertiller, Schwick y Kienast- el «Urban sprawl is visually perceptible. A landscape suffers from urban sprawl if is permeated by urban development or solitary building» (Jaeger et al., 2010, 400).

3 Producidas por la gentrification (elitización) en Santa Cruz de Tenerife. 
En Europa, y con la entrada en vigor de nuevas directrices políticas relacionadas con la Estrategia Territorial Europea, (Romero y Farinós, 2004 o Hildebrand, 2002), se trata de contrarrestar este efecto, ya que el desarrollo de la dispersión urbanística atenta a los tres objetivos básicos de la ETE. En primer lugar, evita el desarrollo de un sistema urbano policéntrico y equilibrado, rompiendo con la construcción de los nuevos tipos de relaciones entre el ámbito rural y el urbano. En segundo lugar, no garantiza la igualdad de acceso a las infraestructuras y al conocimiento, al contrario, las excluye y las aleja. En tercer lugar, no ayuda al desarrollo sostenible, y acrecienta la gestión irresponsable con el deterioro del patrimonio natural y cultural, y de los paisajes de los que forman parte. En esta misma línea, el Convenio Europeo de Paisaje (ELC), describe una clara preocupación por la aceleración de las transformaciones paisajísticas motivada por la evolución de las técnicas de producción y por las prácticas de la ordenación del territorio, del urbanismo, del turismo, de las infraestructuras, el transporte y el tiempo libre. Son procesos que amenazan la calidad de vida de las poblaciones y especialmente el equilibrio armónico entre las necesidades sociales, la economía y el medio ambiente.

El espacio paraurbano se convierte en el combustible que sigue alimentando la vieja dialéctica de enfrentamiento entre el campo y la ciudad. Es el espacio de conflicto dónde se sustituyen las actividades agropecuarias por otros usos de tipo urbano, industrial, segundas residencias, ocio, deportivo, que combinadas con usos agrarios pierden su condición de uso central. En definitiva, ¿se están produciendo procesos de sustitución o de complementariedad? (Pèlachs, Soriano, Tulla, 2009). El modelo de ciudad o el modelo de territorio es el que hay que poner en duda. Se ha elegido, especialmente en los últimos años, el modelo laxo o disperso y a efectos territoriales, acaba siendo el peor, porque consume demasiado territorio (Folch, 2002). Así, el problema del disperso paraurbano no solo tiene connotacio-

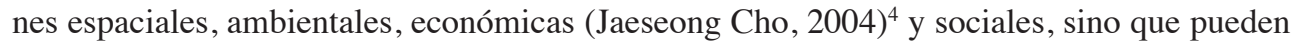
ser catastróficas ante los efectos que puede producir en estos espacios el cambio climático (Huanga, Hua Wang, Budd, 2008). Este fenómeno se ha incrementado en España, especialmente en la última década, 2002-2010, en lo que se ha denominado «el boom inmobiliario» o «el milagro económico español». La dispersión, por tanto, es un profundo equívoco, de sólo aparente levedad, pero que en realidad disemina la prepotencia al ocupar todo el territorio (Pesci, 2002: 106). Hay que tender a la corrección de estas conductas y hacer énfasis en pensamiento como el sostenibilista, donde la disposición de las actividades en el espacio se presenta como una cuestión secundaria, en cuanto que cobran particular valor los umbrales, los ritmos y la naturaleza de los procesos de transformación territorial (Folch). Pensar en paisaje es la clave, la diferencia, no olvidemos en el proceso de planificación, que los paisajes están llenos de lugares que encarnan la experiencia y las aspiraciones de los seres humanos (Nogué, 2007:12).

En Canarias, hay reflexiones muy críticas sobre las consecuencias que el modelo territorial elegido tiene para su mantenimiento sostenible, especialmente en cuanto a la movilidad interior de cada una de las islas (Ramos, 2005). Este problema no hace sino acrecentarse

4 Especialmente en el crecimiento del precio del suelo de todo el espacio afectado por el urban sprawl. 
con las estrategias millonarias en obras públicas previstas ${ }^{5}$. El análisis de accesibilidad para conocer la relación entre municipios residenciales respecto a los centrales desde el punto de vista del mercado laboral en Tenerife, demuestra la inviabilidad del «modelo territorial canario» (Barrios, Godenau y Schorn, en 2009). En esta dirección y usando el Censo de 2001, se abre una nueva fórmula para el análisis de la movilidad residencia-trabajo de la población española (Feria, 2004), permitiendo diagnosticar el problema del crecimiento y dispersión urbanística. La dimensión de la expansión diseminada de baja densidad, en este caso en Madrid, se realiza a través de variables relacionadas con los tipos de barrios, edificación o densidad de población, organizadas en coronas y sectores. (García y Gutiérrez, 2007). Mientras en España estamos analizando el fenómeno, los espacios que primero detectaron el problema de la dispersión urbana se encuentran ya en una fase avanzada de evaluación de las diferentes estrategias y medidas adoptadas para su contención. Un ejemplo es la evaluación de soluciones de cinturones verdes y el establecimiento de bordes de crecimiento urbano como medida de contención en Suiza (Gennaio, Hersperger, Bürgi, 2009). Estos acontecimientos indican la madurez del problema en unas regiones respecto a otras.

En España, en los últimos años, como estrategia vehicular se potencian planes, estrategias, directrices, ordenanzas donde el paisaje es el eje medular. Pero a mi juicio lo que realmente es significativo es el desarrollo de proyectos de mejora en la calidad, protección y gestión del paisaje, especialmente aquellas que conducen a acciones de aplicación directa que mejoren el paisaje. De esta manera, la elaboración de Planes Territoriales de Ordenación del Paisaje, como en Tenerife, la elaboración de Cartas de Paisaje como el del Alt Penedès, el desarrollo de proyectos como el del Parque Patrimonial Fluvial del Ter o el Parque Agrario del Baix Llobregat, o acciones directas de sensibilización sobre paisaje como el Festival Rural de Creación «Las Eras de El Tablero» ${ }^{6}$ (Mejías, Alonso, Vera, Rodríguez, 2011) son algunos de los casos que manifiestan claramente la necesidad de poner freno a la tendencia, que entre otros efectos ha generado el urban sprawl.

La concreción en planes y acciones sobre paisaje manifiesta una clara orientación a nuevos enfoques sobre la ordenación del territorio, esto se manifiesta en el campo aplicado, pero también en todo el entorno formativo académico y profesional ${ }^{7}$. La aprobación y sobre todo la ratificación de España al Convenio Europeo de Paisaje han sido fundamentales (Zoido, Venegas, 2002 o Mata, Tarroja, 2006, Busquets, Cortina 2009).

Los modelos de investigación basados en variables socioeconómicas, se tiene que complementar con componentes y variables espaciales. Por ello y de manera empírica, el objetivo de este artículo es acercarnos al origen de la metástasis de la dispersión urbana aportando a este debate la métrica espacial, y así encauzar el problema desde el punto de vista del paisaje y de la sostenibilidad (Potschin y Haines-Young, 2006), o más recientemente, desde la ecología del paisaje (Jaeger, Bertiller, Schwick, Cavens y Kienast, 2010), aspecto éste que está en mayor consonancia con el Convenio Europeo de Paisaje y con el tratamiento multidisciplinar y transversal que define su complejidad. De hecho, es necesario abordar los diferentes

5 Cierre del «Anillo Insular»-Conexión de las autopista TF-1 y TF-5 por el suroeste de la Isla. Vías exteriores de circunvalación al ámbito metropolitano de Santa Cruz de Tenerife y La Laguna. Construcción de un nuevo puerto en la costa del municipio de Granadilla. Planes ferroviarios, etc.

6 Premio de paisaje 2010. Cabildo Insular de Tenerife, RECEP-ENELP.

7 Colloque international Paysages de la vie quotidienne. Perpignan-Girona. 2011. 
fenómenos, como el de la dispersión edificatoria, no sólo a través del análisis de una o varias componentes que lo pueden explicar en sí mismo, sino a través del complejo mundo de sus relaciones en un espacio explícito. Esto es lo que caracterizaría, dimensionaría y modelaría el problema en una región concreta. «The landscape is essentially a concrete piece of land, and as a consequence, studies and models are spatially explicit» (Naveh y Carmel, 2002).

La aprobación del Plan Territorial Especial de Ordenación del Paisaje de Tenerife $(\text { PTEOPT })^{8}$, es una clara evidencia de la necesidad de aplicar nuevas políticas encaminadas a la preservación de los paisajes. Pero para ello es necesario aplicar las diferentes normas de aplicación directa, las normas directivas de obligado cumplimiento y las recomendaciones, por parte de las administraciones y los particulares. Hecho que me parece de enorme dificultad, pero coincido, que es absolutamente necesario. El diagnóstico fundamental del PTEOPT, recae en el deterioro paisajístico del ámbito cultural (C), especialmente en la medición de su fragilidad. Sin duda, la dispersión del espacio edificado es una de las causas significativas. La normativa del PTEOPT $^{9}$ recomienda tratar las edificaciones en suelo rústico atendiendo a sus volumetrías, exposición visual, ubicación, colores y materiales de construcción, con el objeto de mimetizar el impacto paisajístico y adecuarlo a las características de cada unidad y subunidad de paisaje. Del mismo modo, para los asentamientos rurales se recomienda la concentración -compactación-, evitando la extensión a través de las líneas de comunicación. Respecto del suelo urbano y urbanizable el plan recomienda la compactación de los solares vacíos y los espacios en ruinas antes que aumentar el perímetro. Se debe reaccionar a la larga provisionalidad del espacio a edificar, ya que mientras se consolida se convierte en un espacio deteriorado, a menudo convertidos en basureros o escombreras. La intervención paisajística mediante ajardinamiento e incluso recuperando espacios de vegetación arbolada con especies autóctonas ayuda a mejorar las condiciones ambientales y paisajísticas de estos lugares. La intensa red de barrancos que atraviesan las diferentes unidades de paisaje en la isla de Tenerife ayuda a construir otro eje fundamental, el de los corredores ambientales, ecológicos o verdes. Su intervención y preservación tanto en laderas y cauces como en los bordes permitirán su continuidad y que estos sean funcionales.

Toda esta normativa propuesta disimularía, entre otras cosas, la dispersión urbanística, pero sin duda, su cumplimiento crearía un modelo para la población. De esta forma, con la implicación de los particulares y con el apoyo de la administración se podría iniciar el cambio de modelo.

\section{MÉTODO}

En este artículo no se ha trabajado con muestras, sino con todas las piezas que forman el espacio edificado. Las escalas utilizadas lo permiten, y la claridad de los resultados son indiscutibles. El objetivo es precisar diagnósticos muy finos, que requieren, por supuesto, propuestas y medidas de ordenación al mismo nivel. En un ámbito insular tan intervenido y micro-fraccionado, como el de Tenerife, es una obligación.

8 Aprobación definitiva 28 de diciembre de 2010. Ver Boletín Oficial de Canarias.

9 Para consultar la normativa del plan: http://www.tenerife.es/planes/PTEOPaisaje/adjuntos/Normativa01.pdf 
Aplico un método de análisis métrico, estadístico, gráfico y cartográfico. En términos generales, el territorio es el objeto, la fuente es cualquier representación del territorio y es, al mismo tiempo, origen y destino. En medio se encuentra la fase de organización de la información geográfica entendida como sistema (Harvey, 1983: 448) ${ }^{10}$. Las fuentes cartográficas formalizan gráficamente instantes de la realidad territorial y, por tanto, sus componentes son medibles y representables. La cartografía es una abstracción ${ }^{11}$ y su análisis es una interpretación selectiva y abstracta de la realidad que registra espacialmente y temporalmente los acontecimientos sociales. Su organización requiere la construcción de una estructura de datos que coincida con los tres momentos o niveles de la información, esto es: en el momento del inventario, en el momento del tratamiento y en el momento de la comunicación de los resultados. Desde la selección de las componentes ${ }^{12}$ territoriales cartografiadas, a través de sus elementos y atributos, estamos elaborando los diferentes elementos del sistema que plantea Harvey. El diseño del modelo de datos en el que se combinen la estructura vertical (niveles de componentes), la estructura horizontal (niveles de formas), y la estructura transversal (nivel de combinaciones), es la cuestión clave (Mejías, 2003) ${ }^{13}$.

El tratamiento de cada componente y la construcción de sus derivados, así como la combinación de las componentes mediante métodos de análisis-síntesis, forman el corpus del tratamiento, y solo a través de este procedimiento logramos un diagnóstico del problema tratado, e incluso en su desarrollo, al establecimiento de estrategias y puesta en marcha de de acciones y medidas para la corrección del problema. El mapa y el gráfico individual o mediante composiciones complejas presentan los resultados visibles de los tres momentos. La gráfica moderna es la imagen transformable y reclasificable que las técnicas elementales ponen a disposición de todos (Bertin, 1987: 21). La aplicación de este método tiene por objetivo general conocer, a partir de la abstracción, el funcionamiento real de una unidad cerrada y buscar las reglas de comportamiento que la caracterizan, a partir de ahí, compararla con otras unidades. Es necesario aislar la complejidad territorial en componentes, variables y elementos en un sistema acotado ${ }^{14}$, aunque sabiendo que pertenece a conjuntos más amplios, de otras escalas, e incluso globales. De ahí la dimensión de múltiples niveles que planteo en este artículo: la escala global -macro- la isla, la escala local-micro- el paraje catastral.

¿Cómo explicamos el comportamiento? La metodología MOLAND ${ }^{15}$, establece tres fases para explicar el urban sprawl: La fase de detección del cambio, la comprensión del cambio y la producción de futuros escenarios. En este artículo centro el interés en las dos primeras y para ello construyo el análisis temporal en dos momentos diferentes para cada una de las unidades de referencia. La escala insular se analiza a partir de los elementos planimétricos del mapa topográfico del Cabildo Insular de Tenerife de 1964 y el mapa topográfico de

$10 S=\{A, R\}$ Harvey, utiliza la definición matemática de Klir y Valach en 1967.

11 Según Harvey, el análisis de sistemas no puede llevarse a cabo sin la abstracción y el cierre. Pág. 446.

12 Cualquier sistema real se caracteriza «por una infinidad de variables entre las cuales diferentes observadores (con fines distintos) habrán realizado una infinidad de selecciones». Pág. 446.

13 Tesis doctoral.

14 Según Hagen (1961) «Para que puedan ser de utilidad en el análisis, los sistemas deben de ser cerrados. Un sistema en interacción con su entrono es un sistema abierto: todos los sistemas reales son, por tanto, abiertos. Págs. 445-446.

15 Monitoring Land Use Dinamics. Una base de datos de 28 áreas urbanas y 6 regiones más amplias desarrolladas desde 1998 por el JRC (Joint Research Centre) del IES (Institute for Environment and Sustanaibility). 
GRAFCAN ${ }^{16}$ a escala 1:5000. La local, es desarrollada a partir de los datos gráficos y alfanuméricos del Catastro de Naturaleza Rústica de 1956 y 1991 a escala 1:2500.

La elección de todo el espacio insular, es el mejor sistema acotado, tal y como plantea Harvey. Permite definir claramente el límite, este es finito, y por ello la medición y la relación entre las componentes territoriales son adecuadas. Pero el espacio-isla encierra multitud de matices y comportamientos que la diferencian, de ahí la necesidad de definir unidades de paisaje en función a la caracterización de sus componentes. Considero que la unidad mínima de referencia ${ }^{17}$ es el paraje catastral definido en el catastro de naturaleza rústica de $1956^{18}$. Los dos espacios de análisis están claramente delimitados. Sí bien el análisis insular dimensiona y distribuye el alcance del urban sprawl y su relación con las componentes que lo alimentan (viario y edificación), es el análisis del paraje catastral, socialmente reconocido y cartografiado, el que permite llegar al origen del proceso y su metamorfosis. Aquí tiene el origen del virus, o al menos, uno de los factores que causa el desarrollo de la dispersión urbanística. Obviamente, no todos los parajes catastrales tienen el mismo desarrollo, por tanto habrá diferentes comportamientos, en función a la unidad o subunidad de paisaje en el que se ubiquen. De ahí la complejidad y riqueza de la información obtenida.

Mediante la utilización de indicadores que miden la diversidad del paisaje ${ }^{19}$ empleados en la metodología CORINE Land Cover $^{20}$ evalúo la dispersión de la edificación de la Isla. Interpretar los patrones del paisaje analizando solo el espacio edificado es una manera arriesgada de evaluar el paisaje de una isla, pero su ocupación y distribución es tan importante que afirmaría que es la componente que más atenta a los objetivos de la calidad paisajística. El espacio edificado está destruyendo aspectos característicos y significativos del paisaje. No garantiza el mantenimiento regular de un paisaje, y además, está dificultando enormemente la ordenación del territorio y del paisaje. Estos efectos causados por el urban sprawl hacen necesario la intervención política sobre el control de la dispersión urbanística. Los resultados obtenidos explican un modelo de ocupación del territorio que permite compararlo con otras regiones, fundamentalmente insulares.

\section{DISEÑO DE UN MODELO DE DATOS PARA EL ANÁLISIS MÉTRICO DEL ESPACIO EDIFI- CADO DE LA ISLA DE TENERIFE}

El avance del PIOT publicaba que «Tenerife se ha caracterizado siempre como un poblamiento disperso, con numerosos núcleos de tamaño y dinámica dispar...» (Sabaté, 1994). Para fortalecer esta conclusión es necesario medir los patrones que le caracteriza y analizar su comportamiento.

Al igual que la metodología CORINE Land Cover, selecciono indicadores que miden la particularidad de los paisajes. Valorar su riqueza, diversidad, nivel de heterogeneidad u

16 http://www.grafcan.es/

17 En el PTEOP de Tenerife, esta unidad mínima se define estableciendo los límites de los topónimos (U3).

18 Fuente fundamental para la elaboración de mi tesis doctoral: «Tensiones espaciales en el suelo rústico...»

19 Un trabajo en el que se aplica este análisis es el realizado por F. Javier Gallego, Paula Escribano y Susan Christensen, Comparability of landscape diversity indicators in the European Union.

20 CORINE (Coordination of information on the environment) programa de la Comisión Europea. Los resultados se publicaron en diciembre de 1986. 
homogeneidad, regularidad o irregularidad y dispersión son importantes para caracterizar y evaluar los tipos de paisaje, permitiendo su comparación con otras unidades de referencia (Gallego, Escribano y Christensen, 2000).

La distribución espacial de las barreras, los conductos y las áreas de elevada heterogeneidad, determinan la resistencia del flujo o movimiento de las especies, energía, materiales, e interrumpe un paisaje (Forman, 1995). Considero que el espacio edificado y su relación con el viario de Tenerife ejercen una gran resistencia en los ritmos de los flujos y desarrollo del resto de elementos de la estructura biótica y cultural del paisaje. Para conocer el peso de esa resistencia realizo un análisis métrico, mediante el diseño y construcción de un modelo de datos que explique la complejidad de la mancha del espacio edificado (Vila, Varga, Llausàs y Ribas, 2006). Los conceptos seleccionados son patrones que definen la complejidad del paisaje, por ello, la estructura del modelo de datos contiene un ítem para cada uno de ellos (Tabla 1).

Tabla 1

ESTRUCTURA DEL MODELO DE DATOS. INDICADORES

\begin{tabular}{|c|c|c|c|c|}
\hline Indicador & Riqueza & Heterogeneidad & Irregularidad & Diversidad \\
\hline Fórmula & $\begin{array}{c}\text { Número } \\
\text { de clases } \\
m\end{array}$ & $P D=\frac{N}{A}$ & $E D=\frac{P}{A}$ & $\mathrm{H}^{\prime}=-\sum_{i=l}^{m}(P i * \ln P i)$ \\
\hline Ítem & $\mathrm{C}$ & $\mathrm{PD}$ & $\mathrm{ED}$ & $\mathrm{H}^{\prime}$ \\
\hline
\end{tabular}

El concepto de riqueza indica el número de clases existente en una unidad de referencia. Sí la clase «suelo edificado» es una parte de la componente cultural, sus tipos son las que ofrecen la riqueza de la clase. En Tenerife, este indicador corrobora la complejidad del modelo de desarrollo territorial desarrollado. Para utilizar ya una valoración consensuada en la clasificación de tipos de suelo edificado utilizo la propuesta por el PIOT $^{21}$ de Tenerife, en el que se tipifican 8 clases. El concepto de homogeneidad o heterogeneidad de un paisaje explica la fragmentación de las clases. El indicador utilizado es el patch density y se calcula mediante la relación entre la frecuencia (número de piezas) de cada una de las clases (N) y el área de la unidad de referencia (A). La regularidad o irregularidad de las clases se construye a partir del indicador llamado edge density y se define como la relación entre el perímetro (P) de cada clase y la superficie de la unidad de referencia (A). El índice de diversidad de Shannon (SHDI) cuantifica la diversidad del espacio edificado. Se basa en dos componentes, por un lado, el número de clases $(m)$, que cualifica la riqueza y por otro lado la distribución geográfica proporcional $(\mathrm{Pi})$ que establece la uniformidad entre las diferentes clases en una unidad de referencia $(i)$. Cuanto mayor es el número de clases en una unidad de referencia más equitativa es la distribución geográfica proporcional de cada clase.

21 BOLETÍN OFICIAL DE CANARIAS (2002): «Decreto 150/2002, de 16 de octubre, por el que se aprueba definitivamente el Plan Insular de Ordenación de Tenerife». № 140. Sábado 19 de Octubre de 2002 - 1508. Disponible en http://www.tenerife.es/PIOT/index.asp 


\section{ANÁLISIS DE LA DISPERSIÓN: LA ESCALA INSULAR}

Muchos análisis insulares o regionales utilizan la escala administrativa municipal para explicar las diferentes componentes que le caracterizan. Sí bien esto puede ser muy útil para múltiples aspectos, es una limitación a la hora de estudiar el paisaje. Éste no tiene fronteras administrativas y menos aún trazos rígidos, al contrario, son progresivas, transitivas e irregulares. La identificación y calificación de los tipos de paisaje es una de las medidas específicas que cada administración firmante del Convenio Europeo de Paisaje se compromete a realizar. Un primer aspecto necesario para analizar la isla desde el punto de vista del paisaje es comprobar cómo se estructuran, miden y distribuyen las categorías (ABC) visibles de paisaje (Tabla 2). Un segundo aspecto es analizar y relacionar entre sí y con las categorías de paisaje, dos componentes espaciales estructuradoras del modelo de ocupación territorial actual: el viario, y sobre todo, el espacio edificado.

Tabla 2

CATEGORIASS DE PAISAJE VISIBLE. TENERIFE

\begin{tabular}{|l|c|c|c|}
\hline & ABIÓTICO (A) & BIÓTICO (B) & CULTURAL (C) \\
\hline Frecuencia & 26.497 & 28.013 & 425.359 \\
\hline Suma acumulada $\left(\mathrm{Km}^{2}\right)$ & 171 & 1.204 & 693 \\
\hline Porcentaje (Área) & 8,12 & 59,26 & 32,62 \\
\hline Media (Has.) & 0,64 & 4,47 & 0,16 \\
\hline
\end{tabular}

Fuente: Autor $^{22}$.

\section{El viario. Componente estructuradora y canalizador del modelo de dispersión urbanística}

El complejo entramado viario de la isla de Tenerife merece, por sí mismo, un análisis profundo y monográfico. Aunque este artículo no tiene su foco en profundizar en el análisis estático y dinámico de la red, es necesario, al menos, conocer sus características estructurales ya que parto de la hipótesis de que la red es claramente el eje que facilita y canaliza el fenómeno del urban sprawl. Es una de las prioridades del documento normativo ${ }^{23}$ aprobado del PTEOP, en el que recomienda «evitar la ampliación de los asentamientos rurales siguiendo exclusivamente el trazado de caminos existentes ya que con frecuencia da lugar a estructuras lineales o arborescentes que crean un impacto paisajístico notable así como una percepción de desorden en cuanto a proporciones, formas, colores, orientación e implantación de edificaciones e instalaciones anejas». Por este motivo necesito, para situar también al lector, y a modo de inventario, citar una serie de datos que contextualicen esta componente y su relación con las otras estructuras de paisaje.

22 Trabajos desarrollados a partir del Plan Territorial Especial de Ordenación del Paisaje de la Isla de Tenerife. Aprobación Definitiva. BOC No 254, de 28 de diciembre de 2010.

23 Artículo 25. 


\section{ANÁLISIS DE LA DISPERSIÓN \\ ESCALA INSULAR}

\section{VIARIO}

TIPO DE VIARIO

Indicadores

Suma Acumulada, \% y Densidad
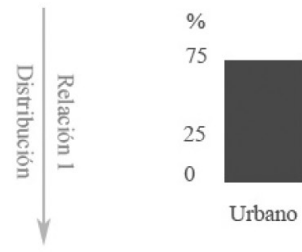

Modelo de organización territorial

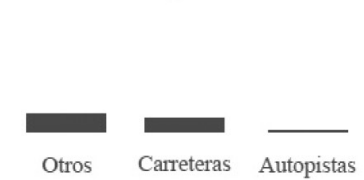

\section{CATEGORÍAS DE PAISAJE}

ABIÓTICO (A)

$26 \%$

Componentes Culturales(Clases) Polígonos interviarios

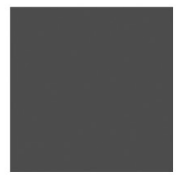

Agricultura

tradicional
BIÓTICO (B)

$15 \%$

$1 \mathrm{~cm}^{2}=5.000$ Has

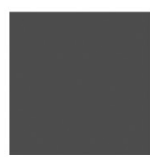

Edificación urbana
CULTURAL (C) $\mathbf{5 9 \%}$

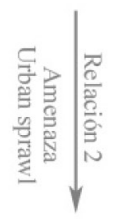

\section{Indicadores}

Frecuencia Suma acumulada (Has.)

Fuente: Autor.

Tenerife tiene 10.200 kilómetros de vías en el año 2009. Posee una densidad de 5Km/ $\mathrm{Km}^{2}$ de viario. Para explicar su distribución utilizo la variable «tipo de viario», un indicador que demuestra claramente el modo de organización territorial (Fig. 1) y su evidente relación con la forma del asentamiento y los espacios agrarios -otros- (Tabla 3). En 2008 comunicamos que, existe un aumento real de la distancia desde periferia hasta los centros urbanos. Este hecho está provocado por el «urban sprawl» descontrolado, que aumenta la distancia espacial, pero también la temporal, haciendo necesaria la utilización del vehículo privado, al carecer de medios de transporte públicos eficientes (Mejías, García y Pérez, 2008) ${ }^{24}$. Esta

24 XI Coloquio Ibérico de Geografía. Alcalá de Henares, Pastrana. Octubre de 2008. Puede leerse en: http:// www.geogra.uah.es/web_11_cig/cdXICIG/docs/01-PDF_Comunicaciones_coloquio/pdf-4/com-P4-30.pdf 
realidad es generalizada para Europa, donde la utilización del vehículo propio se ha incrementado en un 38\% entre 1990 y 2004 y el viaje en coche, a menos de $5 \mathrm{Km}$ supone el $50 \%$ de los viajes y donde el viaje a menos de $3 \mathrm{Km}$ supone el $30 \%{ }^{25}$. Además, el transporte público, en estas circunstancias, tiene poca frecuencia y muchas paradas. La dispersión urbana también limita la movilidad (O’Meara, 2004) y los ciudadanos no pueden participar de igual manera en las actividades cotidianas provocando desigualdades entre diferentes espacios geográficos. Estos hechos son más acusados entre la población más desfavorecida, niños, ancianos y mujeres (Katz, 2000).

Tenerife con una población de 908.555 habitantes (2011) es la isla más poblada del archipiélago canario. Su densidad es de $446,60 \mathrm{Hab} / \mathrm{Km}^{2}$, pero sí el cálculo lo hacemos solo sobre el espacio cultural (C), la concentración de población es de $1.311 \mathrm{Hab} / \mathrm{Km}^{2}$. Este dato si refleja la realidad visible de la ocupación del suelo y justifica la enorme dificultad de ordenación territorial que ello genera. Esta densidad sitúa a Tenerife (C) como una de las regiones más pobladas del mundo, sólo superada por Bahrein, Hong Kong, Singapur, Mónaco y Macao (China) ${ }^{26}$. Esta población se incrementa con los 5.160.203 turistas alojados en Tenerife en el año 2011 -4.851.325 en 2010-, que se concentran en determinados núcleos y enclaves turísticos, pero que se mueven por el entramado viario de toda la isla.

Tabla 3

CLASES DE VIARIO EN 2009. TENERIFE

\begin{tabular}{|l|c|c|c|}
\hline \multicolumn{1}{|c|}{ TIPO VIARIO } & $\begin{array}{c}\text { SUMA ACUMULADA } \\
(\mathbf{K M})\end{array}$ & $\%$ & $\begin{array}{c}\text { DENSIDAD } \\
\text { KM VIARIO/KM }\end{array}$ \\
\hline Autopista & 271,52 & 2,66 & 0,13 \\
\hline Carretera convencional & 963,76 & 9,44 & 0,47 \\
\hline Viario urbano & 7705,51 & 75,55 & 3,79 \\
\hline Otros & 1258,80 & 12,35 & 0,61 \\
\hline
\end{tabular}

Fuente: GRAFCAN. Autor

El peso poblacional descrito necesita disponer de infraestructuras que garanticen la movilidad. Las políticas llevadas a cabo, en los últimos 30 años, se han dirigido a aumentar la cantidad de infraestructuras para vehículos (Tabla 3). En los últimos años, se pone énfasis en infraestructuras para transporte colectivo, como es el caso de las dos líneas de tranvía dentro del área metropolitana que cubren los centros de las ciudades de Santa Cruz de Tenerife y San Cristóbal de La Laguna (2007), y los proyectos insulares para la construcción de líneas de trenes hacia el sur de la isla. Esto se refuerza con el cierre del «Anillo Insular» mediante el enlace de las dos autovías. ¿Por qué estas políticas? Los datos indican que en Tenerife se registran 663.806 automóviles en el año 2009, sí relacionamos este dato con la población que

25 Comisión Unión Europea (2007): «Plans Preparatory Document in relation to the follow-up of the Thematic Strategy on the Urban Environment. Technical Report. Main document, 25 September 2007». Pág. 8. Sprawling conurbations: more car dependency and increased car travel lengths.

26 The World Bank. Densidad de población 2010.

http://data.worldbank.org/indicator/EN.POP.DNST/countries?display=default 
podría tener permiso de conducción de automóviles (+18 años) el número de automóviles por habitante es de 0,90. Esto explica la importancia de la densidad de vías existentes, también podría justificar las nuevas infraestructuras para la movilidad, pero también explica la necesidad del automóvil para enhebrar la dispersión de la edificación.

Las consecuencias de este proceso, así como el escenario futuro lo sintetizo en dos relaciones (Tabla 4, 5):

Tabla 4

RELACIÓN 1: VIARIO-CATEGORIASS DE PAISAJE

\begin{tabular}{|l|c|c|c|}
\hline & ABIÓTICO & BIÓTICO & CULTURAL \\
\hline Frecuencia & 9.530 & 8.925 & 89.618 \\
\hline Suma Acumulada (Has.) & 11.226 & 6.549 & 25.217 \\
\hline Suma Acumulada $\left(\mathrm{Km}^{2}\right)$ & 112,26 & 65,49 & 252,17 \\
\hline
\end{tabular}

Fuente: Autor

La primera relación se construye entre las categorías de paisaje y el viario (Tabla 4). Sí relaciono el espacio bruto ocupado por el cultural (C), con los polígonos interviarios de este ámbito, la superficie vinculada es del $36 \%$. Sí se sigue la lógica de expansión urbana a través de esta red, y que el PTEOP recomienda evitar, es indudable que el riesgo de transformación del espacio cultural es muy elevado. La segunda relación se construye entre las clases culturales y el viario. Sí la dinámica de consolidación a través de la red continúa, son los ámbitos de suelo agrícola productivo los que canalizan el riesgo de transformación hacia lo urbano (Tabla 5). Es necesario, por tanto, tomar medidas de control sobre esos riesgos.

Tabla 5

RELACIÓN ENTRE LAS CLASES CULTURALES Y EL SISTEMA VIARIO

\begin{tabular}{|l|c|c|}
\hline \multicolumn{1}{|c|}{ CLASES } & FRECUENCIA & $\begin{array}{c}\text { SUMA ACUMULADA } \\
\text { (Has) }\end{array}$ \\
\hline Agricultura de exportación (Plátanos, tomates...) & 1.369 & 1.820 \\
\hline Cereales, papas, huerta y frutales templados & 19.652 & 10.220 \\
\hline Edificación rural & 864 & 193 \\
\hline Edificación urbana & 8.106 & 8.836 \\
\hline Viñedos y asociaciones & 2.922 & 1.849 \\
\hline
\end{tabular}

Fuente: Autor

\section{La edificación. Componente (producto-resultado) de la dispersión territorial}

El análisis del asentamiento es retratado en dos momentos temporales claves en el desarrollo territorial de la isla de Tenerife: 1964 y 2002. El año 1964 se puede considerar como la frontera del cambio de modelo económico, social y territorial, en el que la industria turística juega un papel clave. El año 2002 es el momento en el que se ha producido en Canarias 
un hecho relevante. El modelo territorial basado en el crecimiento urbanístico empieza a descontrolarse. El PIOT de Tenerife acaba de aprobarse definitivamente, pero, fundamentalmente, fruto de este proceso de desarrollo territorial desintegrado e insostenible se redacta y aprueba en el año 2003 la Ley 19/2003, de 14 de abril, de Directrices de Ordenación General y las Directrices de Ordenación del Turismo de Canarias ${ }^{27}$. Reconoce esta ley, la desintegración y desequilibrio de la configuración territorial donde no existe una clara diferenciación entre lo rural y lo urbano y donde la dispersión de servicios hace necesariamente el aumento de la movilidad. Por ello, se hace necesario legislar para preservar la conservación de los recursos naturales así como los suelos de interés agrario, litorales y de valor paisajístico, considerándolos además como recursos estratégicos. Por tanto, como indica la ley, es necesaria la compactación de los núcleos de población para tener un uso más eficiente del suelo mediante la densificación y llevar a cabo políticas de contención urbana. Esta ley pretendió dar un giro al modelo de ordenación, y con ello al paisaje y la calidad del medio, los cuales, se convierten en protagonistas. El PTEOP de Tenerife es fruto de este cambio de modelo. Lo sucedido entre el 2002 y la actualidad permitirá evaluar sí las directrices y planes desarrollados son capaces de cambiar el modelo, con la complejidad añadida del proceso de crisis inmobiliaria, primero, y general, después, en la que está sumida España y Canarias en particular. Esta hipótesis no será desarrollada en este artículo pero si abre una línea a continuar en sucesivas investigaciones.

Para analizar el espacio edificado utilizo la división ya establecida y consensuada por el PIOT. Se divide en tres grandes categorías y ocho clases. Las categorías se agrupan en núcleos, enclaves y edificación dispersa. Con esta agregación mido el grado de homogeneidad, regularidad y dispersión para cada una de las categorías (Fig. 2, Tabla 7). Los resultados determinan que el modelo de ocupación de la edificación en Tenerife es disperso (63\%) y ocupa el $40 \%$ de la superficie de suelo edificado. Esta tendencia hacia la dispersión aumenta desde 1964, ya que en ese periodo el modelo era mucho más concentrado, las manchas de suelo edificado aumentan y se fraccionan teniendo como consecuencia una reducción media de $100 \mathrm{~m}^{2}$ entre 1964 y 2002 (Fig. 3).

El modelo de organización territorial tradicional siempre ha tenido una máxima, la preservación del suelo productivo agrario, esta regla o patrón no escrito responde al conocimiento del lugar, especialmente en los ámbitos rurales. La selección de los espacios no productivos para la localización de la residencia o cualquier otro espacio edificado era lo habitual. El resultado de la aplicación de este conocimiento es la materialización de núcleos concentrados o el desarrollo de una dispersión de la edificación mediante la consolidación de una porción de la propiedad y la preservación del resto como espacio productivo, o como reserva de suelo edificable para la reproducción de la familia y según sus necesidades (crecimiento necesario). La ruptura de esos patrones, donde no se le da importancia al suelo productivo agrario, y solo se ve como reserva de suelo urbano, y sobre todo donde el crecimiento no es necesario sino especulativo y las formas y tipos de edificación son estandarizadas y consumidoras de suelo, son efectos del cambio de modelo (Tabla 5). El crecimiento del espacio edificado ha sido tan intenso, que en la actualidad supone el 17\% del ámbito cultural. Además, la relación entre el número de piezas edificadas y su superficie media indican patro-

27 BOC $\mathrm{n}^{\circ} 73$ de 15 de abril de 2003. 
nes (Tabla 6, 7) de concentración en el modelo de $1964\left(\operatorname{Mod}_{64}<n_{l},>\mu\right)^{28}$ y de dispersión en $2002\left(\operatorname{Mod}_{02}=n_{1},<\mu\right)$

Figura 2

MÉTODO ANALÍTICO DE LA EDIFICACIÓN

\section{ANÁLISIS DE LA DISPERSIÓN ESCALA INSULAR}

EDIFICACIÓN

COMPORTAMIENTO DEL ESPACIO EDIFICADO

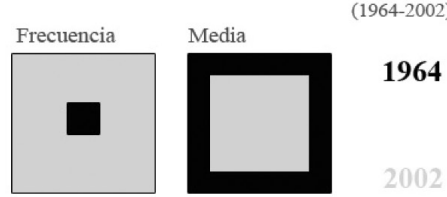

\section{CATEGORÍAS DEL ESPACIO EDIFICADO 2002}

$\begin{array}{cccc} & \text { NÚCLEOS } & \text { ENCLAVES } & \text { DISPERSO } \\ \begin{array}{c}\text { Superficie } \\ \text { Acumulada }\end{array} & 47,01 \% & 13,11 \% & \mathbf{3 9 , 8 8 \%} \\ \text { Frecuencia } & 26,66 \% & 8,69 \% & \mathbf{6 4 , 6 5 \%}\end{array}$

METODOLOGÍA CORINE LAND COVER

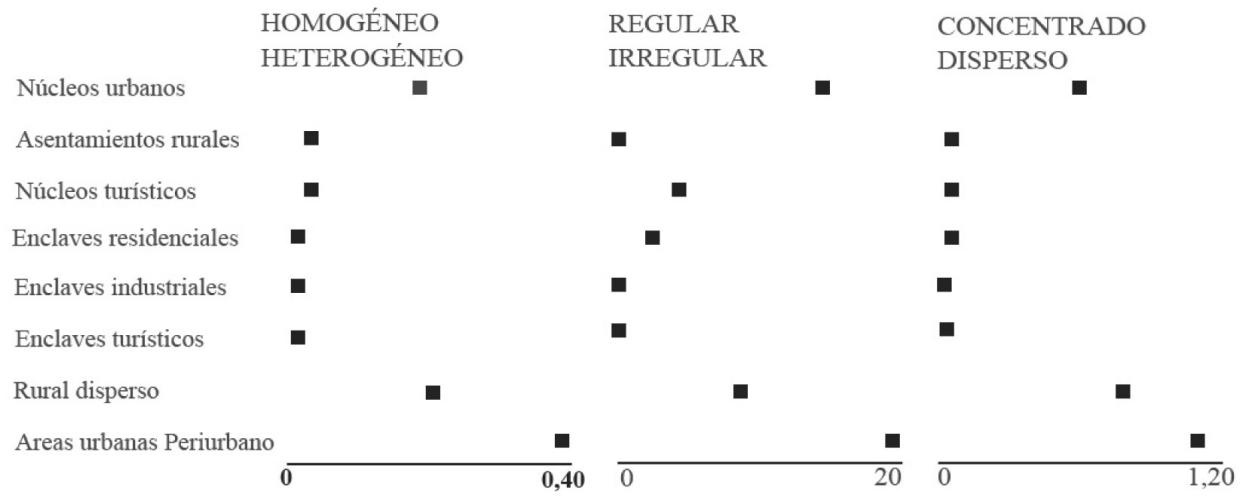

Fuente: Autor.

$28 n_{l}=$ frecuencia; $\mu=$ media 
Tabla 6

CATEGORIAS Y CLASES DE ESPACIO EDIFICADO. 2002. TENERIFE

\begin{tabular}{|l|l|c|c|c|}
\hline \multirow{2}{*}{ CATEGORÍAS } & \multicolumn{1}{|c|}{ CLASES } & FRECUENCIA & $\begin{array}{c}\text { MEDIA ÁREA } \\
\mathbf{m}^{2}\end{array}$ & $\begin{array}{c}\text { SUMA } \\
\text { ACUMULADA } \\
\text { HECTÁREAS }\end{array}$ \\
\hline \multirow{3}{*}{$\begin{array}{l}\text { NÚCLEOS } \\
(\text { N) }\end{array}$} & Núcleos Urbanos & 34.626 & 448 & $1.550,87$ \\
\cline { 2 - 5 } & Núcleos Turísticos & 8.065 & 450 & 362,72 \\
\cline { 2 - 5 } & $\begin{array}{l}\text { Asentamientos Rurales } \\
\text { Tradicionales }\end{array}$ & 6.209 & 158 & 97,86 \\
\hline \multirow{2}{*}{$\begin{array}{l}\text { ENCLAVES } \\
(\mathbf{E})\end{array}$} & Residenciales & 8.313 & 237 & 197,03 \\
\cline { 2 - 5 } & Turísticos & 5.163 & 322 & 166,01 \\
\cline { 2 - 5 } & Enclaves Industriales & 2.470 & 803 & 198,30 \\
\hline \multirow{2}{*}{ DISPERSO } & $\begin{array}{l}\text { Edificación urbana } \\
\text { (Periurbano) }\end{array}$ & 76.496 & 176 & $1.344,43$ \\
\cline { 2 - 5 } & Rural Disperso & 42.111 & 86 & 361,98 \\
\hline
\end{tabular}

Fuente: Autor.

Tabla 7

INDICADORES DE PAISAJE Y CLASES DE EDIFICACIÓN. TENERIFE 1964-2002

\begin{tabular}{|c|c|c|c|c|c|c|c|c|}
\hline \multirow{2}{*}{ CLASES EDIFICACIÓN } & \multicolumn{2}{|c|}{ FRECUENCIA } & \multicolumn{2}{l}{ HOMOGENEIDAD } & \multicolumn{2}{l|}{ REGULARIDAD } & \multicolumn{2}{c|}{ DISPERSIÓN } \\
\cline { 2 - 10 } & C_64 & C_02 & PD_64 & PD_02 & ED_64 & ED_02 & H'_64 & H'02 \\
\hline N. urbanos & 10.933 & 34.626 & 0.05 & 0.17 & 5.61 & 15.55 & 0.90 & 0.50 \\
\hline N. turísticos & 553 & 8.065 & 0.002 & 0.03 & 0.30 & 3.52 & 0.04 & 0.11 \\
\hline A. rurales tradicionales & 2.442 & 6.209 & 0.01 & 0.03 & 0.72 & 1.65 & 0.20 & 0.09 \\
\hline E. residenciales & 319 & 8.313 & 0.001 & 0.04 & 0.10 & 2.59 & 0.02 & 0.12 \\
\hline E. Industriales & 366 & 2.470 & 0.001 & 0.01 & 0.15 & 1.21 & 0.03 & 0.03 \\
\hline E. turísticos & 262 & 5.163 & 0.001 & 0.02 & 0.08 & 1.88 & 0.02 & 0.07 \\
\hline Rural disperso & 6.991 & 42.111 & 0.03 & 0.20 & 1.45 & 7.53 & 0.57 & 0.61 \\
\hline A. urbanas (periurbano) & 10.956 & 76.496 & 0.05 & 0.37 & 3.73 & 20.23 & 0.90 & 1.12 \\
\hline
\end{tabular}

Fuente: Autor.

\section{DIAGNÓSTICO}

El modelo de desarrollo territorial de la Isla de Tenerife realizado en el periodo analizado (1964-2002), presenta a modo de síntesis los siguientes resultados:

1. El suelo edificado ocupa el $22 \%$ del total del espacio cultural. Es más del doble de la superficie ocupada por la agricultura de exportación (9\%) y un tercio de la superficie ocupada por el resto del espacio productivo agrario (64\%). 
Figura 3

ESPACIO EDIFICADO. TENERIFE 1964-2002. FUENTES: M.T CABILDO INSULAR DE TENERIFE 1964; M.T. GRAFCAN 2002. ESCALA 1:5000

\begin{tabular}{lcccccc}
\hline & $\begin{array}{c}\text { FRECUENCIA } \\
\left(n_{i}\right)\end{array}$ & $\begin{array}{c}\text { SUPERFICIE } \\
\text { MÁXIMA } \\
\text { HA }\end{array}$ & $\begin{array}{c}\text { SUMA } \\
\text { ACUMULADA } \\
\text { HA }\end{array}$ & $\begin{array}{c}\text { MEDIA } \\
\mathrm{M}^{2}\end{array}$ & $\begin{array}{c}\text { DESVIACIÓN } \\
\text { ESTÁNDAR } \\
\mathrm{M}^{2}\end{array}$ & PATRÓN \\
\hline 1964 & 41099 & 1,65 & 1375 & 334,67 & 686,79 & CONCENTRADO \\
2002 & 183453 & 5,47 & 4279 & 233,26 & 589,52 & DISPERSO \\
\hline Diferencia & $\mathbf{1 4 2 3 5 4}$ & $\mathbf{3 , 8 2}$ & $\mathbf{2 9 0 3}$ & $-\mathbf{1 0 1 , 4 1}$ & $\mathbf{- 9 7 , 2 7}$ & \\
\cline { 1 - 4 } & & & & & &
\end{tabular}

ESPACIO EDIFICADO EN 1964

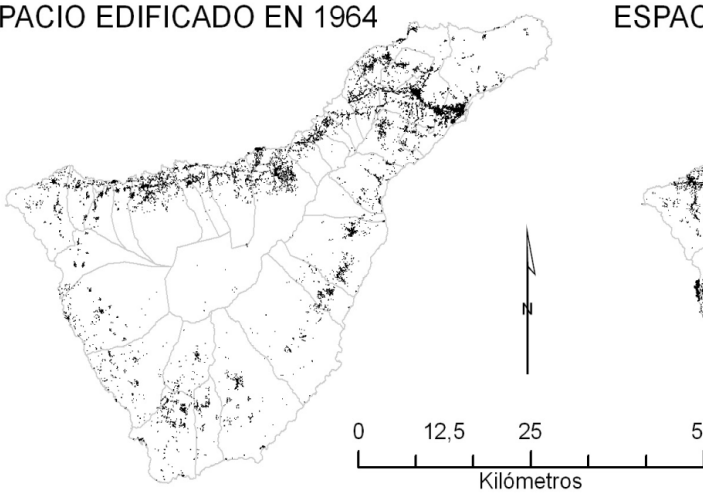

ESPACIO EDIFICADO EN 2002

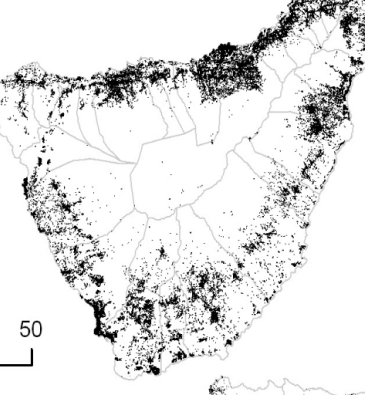

\section{COMPORTAMIENTO 1964-2002}

Comportamiento

Autopistas

División municipal
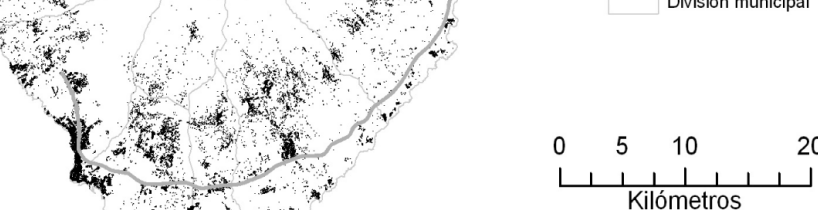

$-t^{3}+2+1$

Fuente: Autor 
2. El crecimiento urbanístico se sustenta fundamentalmente en procesos de dispersión, especialmente en el periurbano y el rústico disperso (Figura 3).

3. El modelo desarrollado rompe claramente con el modelo tradicional de concentración y máxima eficiencia del espacio productivo agrario, representados por asentamientos rurales.

4. Las clases que potencian la dispersión (periurbano y rural disperso) aumentan. El planeamiento diseña la continuidad urbana a través de grandes superficies de suelo urbanizable, que «a modo de encaje de piezas» van colmatando los espacios libres. Este proceso reduce la dispersión, pero también eliminan el espacio productivo agrario, que en muchos casos caracterizan sus paisajes.

5. El resultado de estos procesos de colmatación y dispersión dibujan un paisaje irregular. En un plano intermedio se encuentra el rural disperso. Todo lo contario sucede con el resto de clases, donde la regularidad de su espacio está motivado por su especificidad y concentración (enclaves).

6. Los enclaves tienen comportamientos diferentes; mientras los industriales están más acotados y limitados, los vinculados a los espacios residenciales y los turísticos tienden a un crecimiento moderado de su dispersión.

7. La clase de rural disperso ocupa la misma superficie que la clase de núcleos turísticos. Hay que llamar la atención sobre este hecho, mientras la primera pasa desapercibida, la segunda ha sido muy criticada y demonizada por el impacto y consumo fundamentalmente de suelo.

8. Los asentamientos rurales tradicionales siguen pautas similares a los núcleos urbanos, jugando un papel reorganizador e integrador de las piezas dispersas de su entorno.

9. Si la referencia es el sistema de organización tradicional del territorio, que podría estar representado por los asentamientos rurales tradicionales, comprobamos que aplicando los diferentes indicadores, todas las clases de esta componente distan de ese modelo tradicional. Esto genera una ruptura respecto de la filosofía que el avance del PIOT de Tenerife planteó en 1994, que «los modelos de orden no son necesariamente urbanos. La construcción del territorio aporta también desarrollos formales, voluntades proyectuales que parten de una cultura rural, agraria, longeva y rica, esencialmente distinta de la urbana». Casi dos décadas después se demuestra que no se tuvo en cuenta esta consideración y que el modelo y tipología desarrollados han sido más urbanas que rurales y, lo que es peor, no se ha producido una diferenciación entre las diferentes unidades de paisaje que componen la isla de Tenerife. Las clases de «disperso urbano en periurbano», «rural disperso» y la irregularidad de la estructura de de los «núcleos urbanos» son los causantes de ese hecho.

10. Para ejemplificar cada uno de los indicadores construyo unas viñetas que representan diferentes espacios de la isla de Tenerife (Fig. 4). Podríamos considerar cada uno de estos espacios laboratorios en los que el fenómeno del urban sprawl tiene orígenes diferentes. En cualquier caso, los tres modelos tienen como factor desencadenante el contar con un núcleo urbano como nodo de atracción, a partir del cual se extienden por todo el tejido viario existente. Los extractos gráficos hacen referencia al Valle de La Orotava, al área metropolitana de Santa Cruz de Tenerife y San Cristóbal de La Laguna y al núcleo turístico de Los Cristianos-Las Américas en el sur de la Isla. 
Figura 4

NIVELES DE REGULARIDAD, HOMOGENEIDAD Y DISPERSIÓN APLICADOS AL ESPACIO EDIFICADO

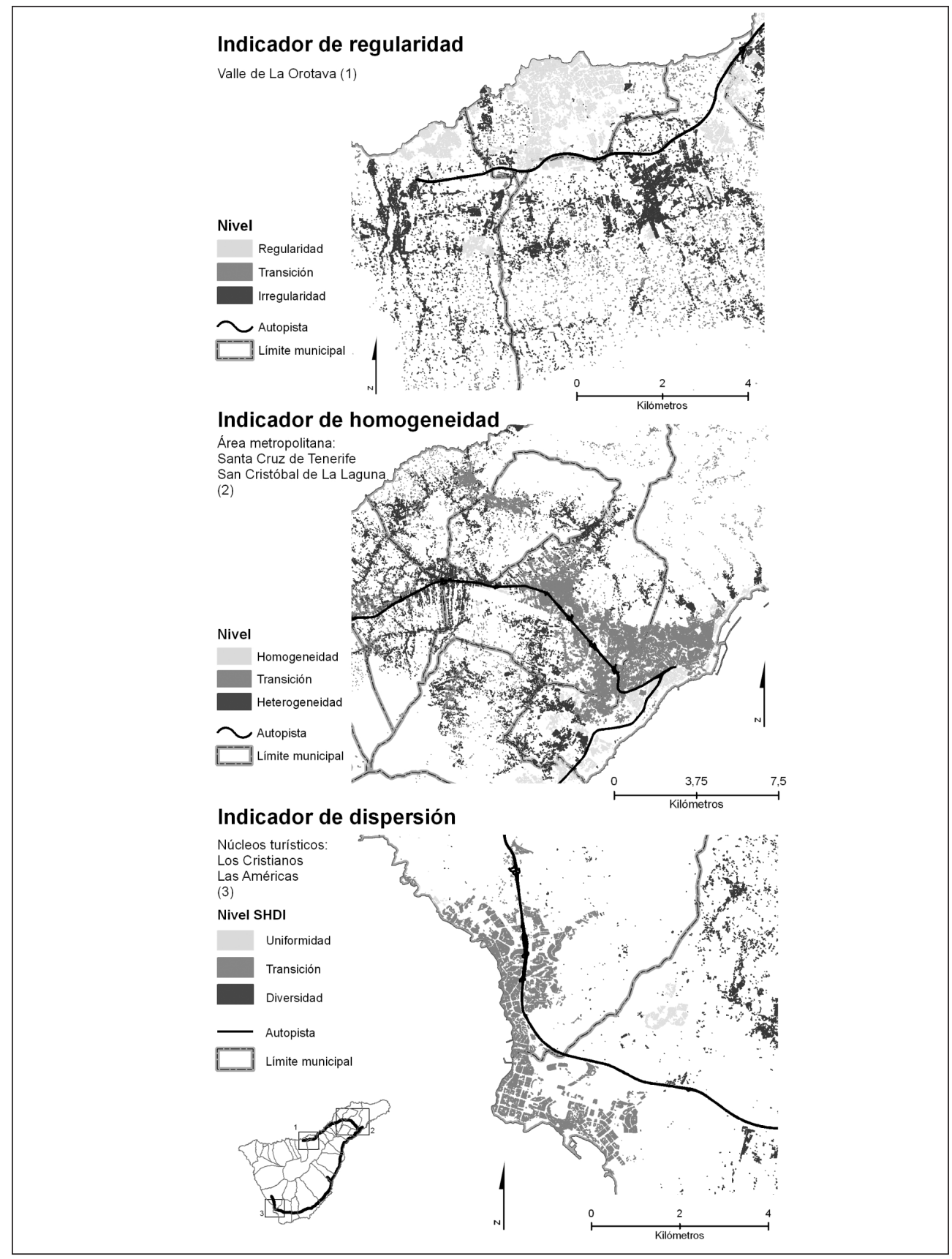

Fuente: GRAFCAN 2002. Escala 1.5000 


\section{LA ESCALA LOCAL}

\section{La evolución del espacio social: El paisaje cultural como proyecto}

No existe un solo modelo que explique y justifique la dispersión urbanística existente. Los indicadores utilizados me permiten, eso sí, modelizar a escala insular la dimensión general y los patrones de organización territorial, pero no las razones de diferenciación que existen en las regiones o unidades de paisaje internas, según la terminología de la Convención Europea de Paisaje.

La metástasis (García, Gutiérrez 2007) ${ }^{29}$ existe, pero, ¿cómo se origina? La trabazón, el misterio de las relaciones que explican los lugares (Maderuelo, 2006) son fundamentales para entender el comportamiento de las regiones. El espacio social esculpido a lo largo de la historia determina, sin duda, la riqueza del paisaje. Éste, siempre en constructo, resultado de una transformación colectiva (Nogué, 2007:11). Su dirección, en una u otra dirección, dependerá del modelo de desarrollo territorial que se elija. Conocer su base paisajística es la clave para determinar su modelo de desarrollo, diferenciado, heterogéneo, auténtico e identitario (Vera, 2008, Mejías, 2008). El concepto de paisaje cultural concreta y dirige esa huella producida por el trabajo ejercido sobre el territorio (Sabaté, 2007). Es sustancial leer cuidadosamente su proceso de construcción, extraer su fuerza formal y tratarlos -todos- como recursos sociales que explican el lugar (Schuster, Sabaté, 2004). Los patrones estructurales y sus reglas de comportamiento orientarán cual debería ser su proyección, siempre articulada en los diferentes instrumentos de ordenación territorial. La realización de una biopsia a un fragmento del espacio afectado por la dispersión urbanística nos ayudará a introducir explicaciones más precisas del origen del fenómeno del urban sprawl. Teniendo en cuenta las diferencias de patrones que puedan existir, me gustaría aportar un caso que podría denominar «diseminación urbanística sobre espacios agrícolas industrializados».

\section{La unidad mínima de análisis: el paraje catastral}

Sintetizaré el caso sustentado en el sector costero oriental del municipio de Arona $(\text { Tenerife })^{30}$. La caracterización alfanumérica catastral de 1956 descubre y emplea unidades analíticas novedosas. Buscar nuevos marcos de referencia vinculados a la estructura espacial nos ayuda a organizar la información geográfica de manera sistémica y, sobre todo, nos abre la puerta para conocer con detalle las reglas y los patrones de comportamiento diferencial (topológicos) que existen entre unas unidades y otras. En este contexto dirijo la atención hacia un espacio paisajísticamente diferenciado, tanto desde el punto de vista de su estructura abiótica, como de su evolución cultural. Tomo por referencia dos instantáneas de la cartografía catastral de naturaleza rústica, 1956 y 1991. Aunque muy distantes entre sí, demuestran la evolución del espacio social, desde un estado semi-estático en 1956, a un espacio dinámico en constante transformación en 1991 (Fig. 5). Así como, el inicio de nuevas estrategias y

29 Utilizan el término de «metropolización metastásica» utilizado por Asher en 1995, para expresar la aparición de elementos metropolitanos en territorios no contiguos ni metropolitanos.

30 Véase nota 14. 
dinámicas de transformación vinculadas, fundamentalmente, a las actividades residenciales y turísticas. La representación manifiesta ese cambio en la estructura espacial.

En una primera fase, a partir de 1930, con la llegada del agua canalizada hasta el sur de Tenerife, la función agraria se desarrollaba en los suelos edáficamente más apropiados y su sistema de cultivo se orientaba al regadío de cultivos de exportación (tomate y plátano). Esta actividad productiva se combinaba con otros cultivos y aprovechamientos marginales de secano orientados al autoconsumo de los trabajadores de las explotaciones de exportación (Martín, 1991, Sabaté, 1993). A partir de los años sesenta, y especialmente en los setenta, se produce el gran cambio en la estructura espacial, en los sistemas de cultivos y en la organización territorial del espacio (Fig. 5). El parcelario catastral evidencia la estructura rectilínea y simétrica de los nuevos modos de producción y las nuevas formas de capitalización emergentes. Los nuevos empresarios agrícolas, en su mayoría emigrantes retornados, con capital y ganas de invertir en el sector agrícola, inmobiliario y, más tarde, turístico, potencian este cambio. Lo hacen en los suelos más inertes y costosos de transformación agrícola, los malpaíses. Pero en los nuevos sistemas empleados el elemento suelo no es tan importante. El despedregado, la sorriba, el sistema viario y las piezas de industrialización agraria crean las bases de verdaderas urbanizaciones. Por otra parte, muchos de los espacios cultivados hasta ese momento se abandonan o, simplemente, entran en un estado de parálisis especuladora, en previsión de los nuevos cambios que se avecinan. Esas tierras, propiedad de los grandes terratenientes en 1956, son vendidas, especialmente aquellas parcelas contiguas o próximas a los espacios urbanos consolidados. Entre los nuevos compradores de estas tierras se encuentran algunas sociedades empresariales, especialmente vinculadas con el sector de la construcción.

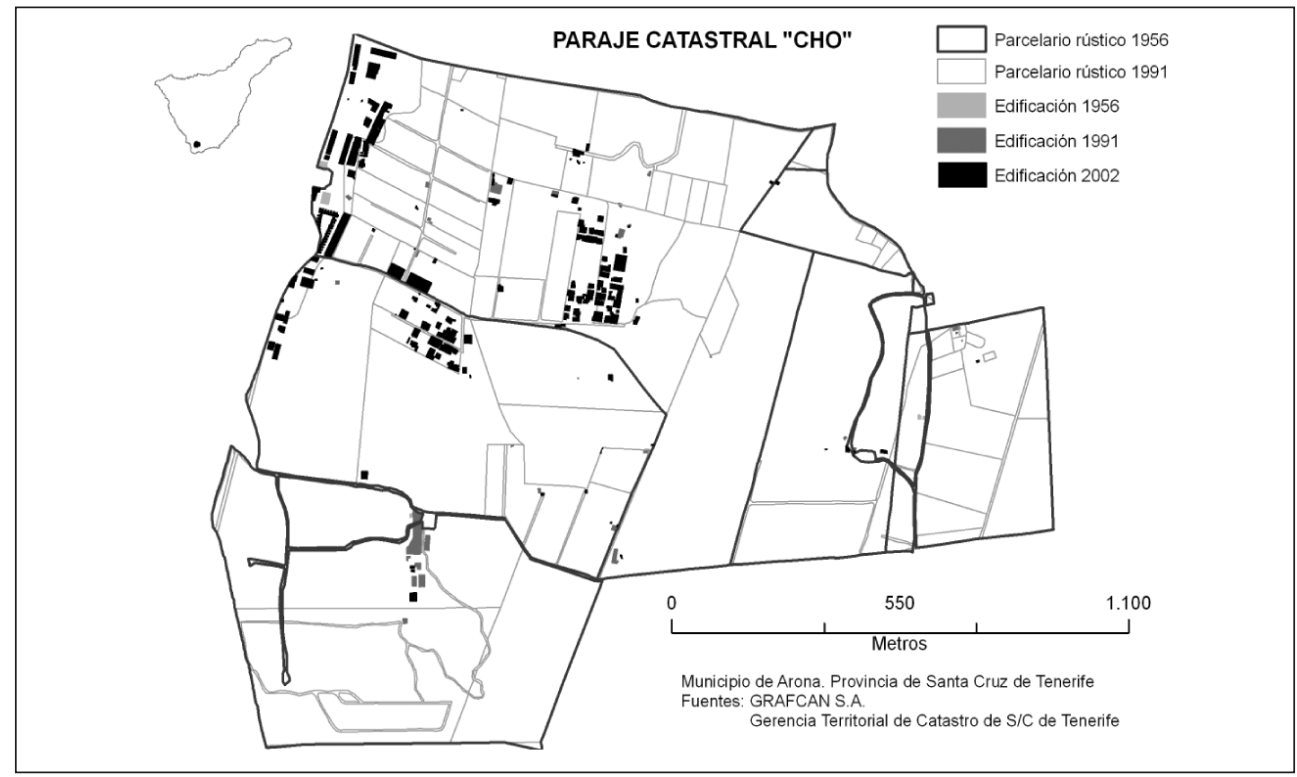


Pero esta fase reciente, que ya se detecta en la fuente de 1991, se sustenta en una nueva forma de desarrollo del capital a partir de la conversión del suelo rústico industrial en suelo urbano. Es aquí donde comienza la urbanización marginal ligada a las estructuras de transformación agrícola (infraestructuras de acceso a explotaciones agrícolas industriales, parcelación de los espacios de cultivo, urbanización mediante carriles de separación de los espacios de cultivo, murados, invernaderos, etc.). Es en este proceso donde el urban sprawl encuentra su mecha, extendiéndose paulatinamente y de manera dispersa entre las diferentes explotaciones.

\section{CONCLUSIONES}

El urban sprawl:

Es un fenómeno global que se manifiesta de múltiples maneras. Se explican como procesos de producción de nuevos espacios como estrategia de reproducción de capital.

Aparece desde los años cincuenta del siglo pasado, replicándose como modelo de desarrollo vinculado fundamentalmente a la expansión del vehículo privado y localización de nuevas actividades como foco de atracción de población. Este hecho se produce de manera desigual en función a las condiciones socio-económicas de los diferentes espacios.

Es tratado con nuevas estrategias de limitación, cinturones verdes, medidas de contención urbana, establecimientos de sistemas urbanos policéntricos, etc. El desarrollo de estas medidas se produce en función de nivel de crecimiento en el que se halle cada espacio.

Debe analizarse no solo desde sus posibles afecciones económicas, espaciales y temporales (tiempo de desplazamiento, costes socio-económicos, distancia-tiempo, etc.) sino también desde los costes ambientales y paisajísticos que están generando.

Por su complejidad y expansión, requiere medidas analíticas más próximas a la ecología del paisaje. Definir el problema y modelizar las consecuencias del mismo es urgente.

Se ha medido en dos escalas. La isla en su conjunto como unidad compleja y extensa. El paraje catastral como unidad mínima y concreta. En el primero se descubre y mide la importancia del fenómeno y su distribución. En el segundo, explico la génesis del fenómeno.

En Tenerife se manifiesta a través de la expansión de la edificación en el espacio periurbano y el rural disperso, sumando ambos la mitad del espacio edificado insular. El tejido urbano tiende a colmatar los espacios libres que la dispersión genera. Esta misma tendencia hace que los asentamientos rurales consoliden su rodeo disperso.

Puede ser medido y comparado con detalle si tomamos como unidades de referencia los parajes catastrales. Es desde esta unidad desde donde podemos descubrir los procesos de transformación del espacio social a través del tiempo y, por tanto, encontrar los detalles de la génesis del problema.

En el paraje de «Cho» se produce transformando el espacio comunal (1956) en suelo urbano (2002) mediando la conversión en suelo rústico y este en rústico industrial.

Requiere un análisis de la red. La transferencia de toda esta información y su modelización a través de ella permitirá descubrir los nuevos escenarios a los que enfrentarnos y, sobre todo, con la posibilidad de medir los costes que este modelo está generando. 


\section{BIBLIOGRAFÍA}

BARRIOS, M.C., GODENAU, D. y SCHORN, J. (2009): «Los mercados locales de trabajo y sus condiciones de accesibilidad en Tenerife». Boletín de la Asociación de Geógrafos Españoles, nº 49, 67-82.

BERTIN, J. (1987): La gráfica y el tratamiento gráfico de la información. Madrid. Taurus.

BOE (2008): Instrumento de Ratificación del Convenio Europeo del Paisaje. № 31.5 febrero.

BUSQUET, J. y CORTINA, A. (2009): Gestión del paisaje. Manual de protección, gestión y ordenación del paisaje. Barcelona. Ariel Patrimonio.

COMISIÓN EUROPEA (1999): Estrategia Territorial Europea (ETE). Hacia un desarrollo equilibrado y sostenible del territorio de la UE. Postdam, Comité de Desarrollo Territorial.

CUSCOY, L.D. (1968): Los guanches. Vida y cultura del primitivo habitante de Tenerife. Santa Cruz de Tenerife. Museo Arqueológico de Tenerife.

CONSEJO DE EUROPA (2000): European Landscape Convention. European Treaty Series No. 176. Disponible en http://conventions.coe.int/Treaty/en/Treaties/Html/176.htm

EEA (2006): Urban Sprawl in Europe. The ignored challenge. Report. No10/2006. JRC.

FERIA, J.M. (2004): «Problemas de definición de las Áreas metropolitanas en España». Boletín de Asociación de Geógrafos Españoles, $\mathrm{n}^{\circ}$ 38, 85-99.

FOLCH, R. (Coordinador) (2003): El territorio como sistema. Conceptos y herramientas de ordenación. Barcelona. Diputación de Barcelona.

FORMAN, R.T.T. (1995): «Some general principles of landscape and regional ecology». Landscape Ecology, vol.10, n 3, 133-144. SPB Academic Publishing.

GALLEGO, F.J., ESCRIBANO P. y CHRISTENSEN, S. (2000) «Comparability of landscape diversity indicators in the European Union» en From Land cover to landscape diversity in the European Union. Disponible en http://e.ceuropa.eu/agriculture/publi/landscape

GARCÍA, L.M. (1981): Santa Cruz de Tenerife: la formación de la ciudad marginal. Santa Cruz de Tenerife. Aula de Cultura de Tenerife.

GARCÍA, L.M., SMITH, N. y MEJÍAS, M.A. (2007). «Gentrification, displacement and tourism in Santa Cruz de Tenerife». Urban Geography, 28, 2, 276-298.

GARCÍA, J.C. y GUTIÉRREZ, J. (2007): «La ciudad dispersa: cambios recientes en los espacios residenciales de la comunidad de Madrid». Anales de Geografía, vol. 27, n 1 , 45-67.

GENNAIO, M., HERSPERGER, A. y BÜRGI, M. (2009): «Containing urban sprawl -Evaluating effectiveness of urban growth boundaries set by the Swiss Land Use Plan». Land Use Policy, 26. 224-232.Science Direct. Disponible en www.elsevier.com

HARVEY, D. (1983): Teoría, leyes y modelos en Geografía. Alianza. Madrid.

HUANGA, SH., HUA WANG, S. y BUDD, W. (2008): «Sprawl in Taipei's peri-urban zone: Responses to spatial planning and implications for adapting global environmental change». Landscape and Urban Planning, 20-32. Disponible en www.elsevier.com/locate/landurbplan

JAEGER, J.A.G., BERTILLER, R., SCHWICK, C. y KIENAST, F. (2010): «Suitability criteria for measures of urban sprawl». Ecological Indicators, $\mathrm{n}^{\circ} 10,397-406$. Disponible en: www.elsevier.com/locate/ecolind 
JAESEONG CHO (2005): «Urban Planning and Urban Sprawl in Korea». Urban Policy and Research, vol. 23, $\mathrm{n}^{\mathrm{o}}$ 2, 203-218. Routledge.

JOHNSON, M.P. (2001): «Environmental impacts of urban sprawl: A survey of the literature and proposed research agenda». Environment and Planning 33, 71-735.

KATZ, C. (2000): «Límites espaciales para la movilidad de las mujeres». En Globalización: Transformaciones urbanas, precarización social y discriminación de género. Edición García, Sabaté, Mejías y Martín. Departamento Geografía, Universidad de La Laguna. Tenerife.

LYNCH, K. (1961): «The pattern of Metropolis». En City sense an city design. (Banerjee, T. y Southworth, M. Ed.). Cambridge, Massachusetts, London, 47-64, MIT Press.

MADERUELO, J. (2006): El paisaje. Génesis de un concepto. Abada Editores, 32-35.

MCHARG, I. (2000): «Una respuesta a los valores». En Proyectar con la Naturaleza, 78-93. GG.

MARTÍN, V. (1991): Agua y agricultura en Canarias: el sur de Tenerife. Las Palmas de Gran Canaria. Benchomo.

MATA, R., TARROJA, A. (Coord.) (2006): El paisaje y la gestión del territorio: criterios paisajísticos en la ordenación del territorio y el urbanismo. Diputación de Barcelona. Barcelona.

MEJÍAS, M.A. (2003): Tensiones espaciales en el suelo rústico entre las actividades agrarias y otras actividades turístico-residenciales. Sector costero oriental del municipio de Arona (Tenerife). Tesis doctoral. Universidad de La Laguna. Inédita.

MEJÍAS, M.A., GARCÍA, I. y PÉREZ, M. (2008): Sistema de movilidad urbana basado en la bicicleta en ciudades de elevada pendiente. El caso del Área Metropolitana de Santa Cruz de Tenerife y San Cristóbal de La Laguna. En XI Coloquio Ibérico de Geografía. Alcalá de Henares, Pastrana. AGE, Universidad de Alcalá y Asociación Portuguesa de Geografía.

MEJIAS, M.A., ALONSO, A.B. VERA, J.R y RODRÍGUEZ, D. (2011): «El Tablero ¿village ou quartier? Vers la consolidation d'une stratégie paysagère. Colloque international Paysages de la vie quotidienne. Perpignan-Girona.

MUÑOZ, F. (2009): «Paisajes metropolitanos» en Gestión del paisaje. Manual de protección, gestión y ordenación del paisaje . (Busquets, J., Cortina, A.) Barcelona. Ariel, 61-75.

NAVEH, Z. y CARMEL, Y. (2002): «Landscape complexity versus ecosystem complexityimplication for landscape planning and management». XII Congresso Nazionale della Società Italiana di Ecologia -S.It.E. Urbino 16-18 settembre. La Complessità in Ecologia.

NOGUÉ, J. (Ed.) (2007): La construcción social del paisaje. Madrid. Biblioteca Nueva.

O’MEARA, M. (2004): Los límites de la ciudad. Cómo frenar la dispersión urbana. Cuadernos Worldwatch. Bakeaz. Centro de Documentación y Estudios para la Paz. Gobierno Vasco, Bilbao.

PESCI, R. (2003): «El urbanismo y la cultura ambiental» En El territorio como sistema: conceptos y herramientas de ordenación. (Folch coord.). Barcelona, Diputación de Barcelona, 101-119.

PELACH, A., SORIANO, J. y TULLA, A. (2009): «Paisajes agrarios» en Gestión del paisaje. Manual de protección, gestión y ordenación del paisaje. (Busquets, J., Cortina, A.) Barcelona. Ariel, 77-94. 
POTSCHIN, M.B. y HAINES-YOUNG, R.H. (2006). «Landscape and sustainability» (Editorial). Landscape and Urban Planning, 75, 155-161.

RAMOS, D. (2005): «Modelo territorial, movilidad insular y sostenibilidad en Canarias: una reflexión crítica». Boletín de la Asociación de Geógrafos Españoles. n 40, 245-268.

SABATÉ, F. (1993): Burgados, tomates, turistas y espacios protegidos: usos tradicionales y transformaciones de un espacio litoral del sur de Tenerife: Guaza y Rasca (Arona). Santa Cruz de Tenerife Caja General de Ahorros de Canarias.

SABATÉ, J. (2007):«Paisajes culturales, identidad y proyecto territorial». En I Simposio Internacional. África, América y Europa. I Bienal de Arquitectura, Arte y Paisaje de Canarias. Gobierno de Canarias, Ministerio de Cultura, 339-341.

SABATÉ, J., C.C.R.S. Arquitectos (1994): PIOT Avance. Plan Insular de ordenación del Territorio. Santa Cruz de Tenerife Cabildo Insular de Tenerife, 148-159.

SABATÉ, J. (Coord.) (2004): Patrimonio y proyecto territorial. Colonias, Sèquia de Manresa y Delta del Llobregat. Espai Blau. Diputació Barcelona.

TARROJA, A. (2009): «La dimensión social del paisaje» en Gestión del paisaje. Manual de protección, gestión y ordenación del paisaje. (Busquets, J., Cortina, A.) Barcelona. Ariel, 239-251.

VERA, J.R. (2008): «Paisaje, identidad local y competitividad territorial: nuevas técnicas de análisis y planificación». En Espacios Turísticos: Mercantilización, Paisaje e Identidad, Ivars Baidal y Vera Rebollo (Editores). Universidad de Alicante, 333-356.

VILA, J., VARGA, D., LLAUSÀS, A. y RIBAS, A. (2006): «Conceptos y métodos fundamentales en ecología del paisaje. Una interpretación desde la geografía» Documents D’Anàlisi Geogràfica. 48, 151-166.

ZOIDO, F y VENEGAS, C. (Coord.) (2002): Paisaje y ordenación del territorio. Junta de Andalucía y Fundación Duque de Soria. 
